\title{
Hydrogen generation by reaction of Si nanopowder with neutral water
}

\author{
Yuki Kobayashi • Shinsuke Matsuda • \\ Kentaro Imamura $•$ Hikaru Kobayashi
}

Received: 2 December 2016/Accepted: 27 April 2017 /Published online: 16 May 2017

(C) The Author(s) 2017. This article is an open access publication

\begin{abstract}
Si and its oxide are nonpoisonous materials, and thus, it can be taken for medical effects. We have developed a method of generation of hydrogen by use of reactions of Si nanopowder with water in the neutral $\mathrm{pH}$ region. Si nanopowder is fabricated by the simple bead milling method. Si nanopowder reacts with water to generate hydrogen even in cases where $\mathrm{pH}$ is set at the neutral region between 7.0 and 8.6. The hydrogen generation rate strongly depends on $\mathrm{pH}$ and in the case of $\mathrm{pH} 8.0, \sim 55 \mathrm{ml} / \mathrm{g}$ hydrogen which corresponds to that contained in approximately $3 \mathrm{~L}$ saturated hydrogenrich water is generated in $1 \mathrm{~h}$. The reaction rate for hydrogen generation greatly increases with $\mathrm{pH}$, indicating that the reacting species is hydroxide ions. The change of $\mathrm{pH}$ after the hydrogen generation reaction is negligibly low compared with that estimated assuming that hydroxide ions are consumed by the reaction. From these results, we conclude the following reaction mechanism: Si nanopowder reacts with hydroxide ions in the rate-determining reaction to form hydrogen molecules, $\mathrm{SiO}_{2}$, and electrons in the conduction band. Then, generated electrons are accepted by water molecules, resulting in production of hydrogen molecules and hydroxide ions. The hydrogen generation rate strongly
\end{abstract}

Electronic supplementary material The online version of this article (doi:10.1007/s11051-017-3873-z) contains supplementary material, which is available to authorized users.

Y. Kobayashi $\cdot$ S. Matsuda $\cdot$ K. Imamura

H. Kobayashi $(\bowtie)$

The Institute of Scientific and Industrial Research, Osaka University, 8-1 Mihogaoka, Osaka, Ibaraki 567-0047, Japan

e-mail: h.kobayashi@sanken.osaka-u.ac.jp depends on the crystallite size of Si nanopowder, but not on the size of aggregates of Si nanopowder. The present study shows a possibility to use Si nanopowder for hydrogen generation in the body in order to eliminate hydroxyl radicals which cause various diseases.

Keywords Hydrogen-rich water $\cdot \mathrm{SiO}_{2} \cdot$ Hydroxide ion . Hydroxyl radical $\cdot$ Medical applications

\section{Introduction}

Hydrogen and hydrogen-rich water attract much interest because of its excellent property to eliminate hydroxyl radicals in our bodies (Ohsawa et al. 2007; Iuchi et al. 2016). It is reported that hydrogen-rich water (or hydrogen) possesses an effect to prevent various diseases such as cancer cell proliferation (Kagawa et al. 2012), memory deterioration (Nagata et al. 2009), Parkinson's disease (Yoritaka et al. 2013; Fu et al. 2009), Alzheimer's disease ( $\mathrm{Li}$ et al. 2010), diabetes (Kamimura et al. 2011), obesity (Kamimura et al. 2011), atopic dermatitis (Yoon et al. 2014), cutaneous senility (Kato et al. 2012), etc.

$\mathrm{Si}$ and $\mathrm{SiO}_{2}$ (i.e., product formed by the reaction of $\mathrm{Si}$ with water to generate hydrogen) are both nonpoisonous, and thus, Si nanopowder can be taken to generate hydrogen in the body. Generated hydrogen is absorbed in the digestive organ and circulates in the vascular system of whole body.

The conventional method to produce hydrogen-rich water utilizes water electrolysis. Disadvantage of this method is needs of electrolysis apparatuses and 
electricity. Another disadvantage is that the hydrogen concentration easily decreases by diffusion to air. Moreover, the saturated hydrogen concentration of hydrogenrich water is only $1.6 \mathrm{ppm}$, and $1 \mathrm{~L}$ hydrogen-rich water includes only $19 \mathrm{~mL}$ hydrogen gas at maximum.

Litvinenko et al. (2010) have reported that porous $\mathrm{Si}$ produced by stain etching reacts with water in the presence of $\mathrm{NH}_{3}$, leading to generation of hydrogen molecules. Bahruji et al. (2009) have shown that irradiation of UV light on Si nanoparticles in deionized water generates hydrogen, resulting from oxidation of $\mathrm{Si}$ nanoparticles. Erogbogbo et al. (2013) have achieved a high hydrogen evolution rate by the reaction of nanosized Si with water having high $\mathrm{pH}$. These studies aimed at hydrogen generation with high rates for energy application, e.g., fuel cells, and these methods using strong alkaline solutions or UV irradiation are not applicable to internal hydrogen generation for medical use.

We have recently developed a simple fabrication method of Si nanopowder using the bead milling method (Maeda et al. 2014; Matsumoto et al. 2014; Matsumoto et al. 2016; Imamura et al. 2016) and shown that fabricated Si nanopowder exhibits visible light photoluminescence due to band-gap widening resulting from the quantum confinement effect (Matsumoto et al. 2016). Although Si bulk does not strongly react with water to generate hydrogen, Si nanopowder easily reacts with it especially in the case of high pH (Erogbogbo et al. 2013; Imamura et al. 2016). At $\mathrm{pH}$ of 13 , for example, the hydrogen evolution rate reaches $580 \mathrm{~mL} / \mathrm{min} \cdot \mathrm{g}$, and the total hydrogen evolution volume is $1.44 \mathrm{~L} / \mathrm{g}$ (Imamura et al. 2016).

In the present study, it is shown that Si nanopowder reacts with water having neutral $\mathrm{pH}$ range between 7.0 and 8.6 to generate hydrogen (or hydrogen-rich water). The present study shows a possibility to generate hydrogen in the human body to eliminate hydroxyl radicals $(\cdot \mathrm{OH})$ which are the possible cause for various diseases such as diabetic vascular disease (Kajiyama et al. 2008), Alzheimer's disease (Maurizi 2001), Parkinson's disease (Ihara et al. 1999), Huntington's disease (Charvin et al. 2005), cataract (Garner et al. 2000), cutaneous aging (Cadenas and Davies 2000; Pillai et al. 2005), etc.

\section{Experimental}

Si nanopowder was produced from Si powder (Koujundo Chemical Laboratory Si 3 N Powder ca. $5 \mu \mathrm{m}$ ) by use of the bead milling method. Si nanopowder was fabricated using the one-step milling method with $0.5-\mathrm{mm}$ diameter zirconia beads for $4 \mathrm{~h}$ or using the two-step milling method with $0.5-\mathrm{mm}$ diameter zirconia beads for $4 \mathrm{~h}$ and then with $0.3-\mathrm{mm}$ diameter zirconia beads for $4 \mathrm{~h}$. For some specimens, etching with $5 \mathrm{wt} \%$ hydrofluoric acid (HF) solutions was carried out to remove a silicon oxide layer on Si nanopowder. Si nanopowder after the HF treatment was hydrophobic due to surface $\mathrm{Si}-\mathrm{H}$ bonds (Jakob et al. 1992; Higashi et al. 1991). Si nanopowder was immersed in ethanol to make the surface hydrophilic and thus to promote surface reaction with water. Si nanopowder of $10 \mathrm{mg}$ with a small amount of ethanol was immersed in $30 \mathrm{~mL}$ water with $\mathrm{pH}$ adjusted between 7.0 and 8.6 by addition of borate buffer. In some cases, water with $\mathrm{pH} 9.0$ was used for hydrogen generation.

The hydrogen concentration in water was detected by use of a TOA DKK-TOA DH-35A potable dissolved hydrogen-meter, and the generated hydrogen volume at $20{ }^{\circ} \mathrm{C}$ was estimated from the hydrogen concentration. $\mathrm{X}$-ray photoelectron spectroscopy (XPS) spectra were recorded using a KRATOS AXIS-165x spectrometer with an $\mathrm{Mg}-\mathrm{K} \alpha$ radiation source.

\section{Results and discussion}

Figure 1 shows the volume of hydrogen generated by the reaction with ultrapure water vs the reaction time for Si nanopowder produced by the one-step milling method with (plot b) and without (plot a) the HF treatment. With HF etching of Si nanopowder, the generated hydrogen volume increased much rapidly with time, and that measured after $6 \mathrm{~h}$ reaction became $\sim 4$ times higher than that without HF etching. Both the plots were almost linear with the reaction time.

Figure 2 shows the hydrogen volume produced by the reactions of Si nanopowder with water having various $\mathrm{pH}$ values. The generated hydrogen volume for $\mathrm{pH} 8.0$ (plot b) solutions increased much faster than that for ultrapure water (plot a). The hydrogen generation rate was further increased by an increase of $\mathrm{pH}$ to 8.6 (plot c). Hydrogen generation of $\sim 55 \mathrm{~mL} / \mathrm{g}$ was achieved in $60 \mathrm{~min}$ for water with $\mathrm{pH} 8.0$ and $25 \mathrm{~min}$ for that with $\mathrm{pH}$ 8.6. Hydrogen generation also proceeded by the reaction with tap water ( $\mathrm{pH}=7.1 \sim 7.4$ ) (plot d). It is noted that $55 \mathrm{~mL}$ hydrogen corresponded to that included in approximately $3 \mathrm{~L}$ saturated hydrogen-rich water although only $3.2 \% \mathrm{Si}$ reacted for hydrogen generation. It should also be noted 


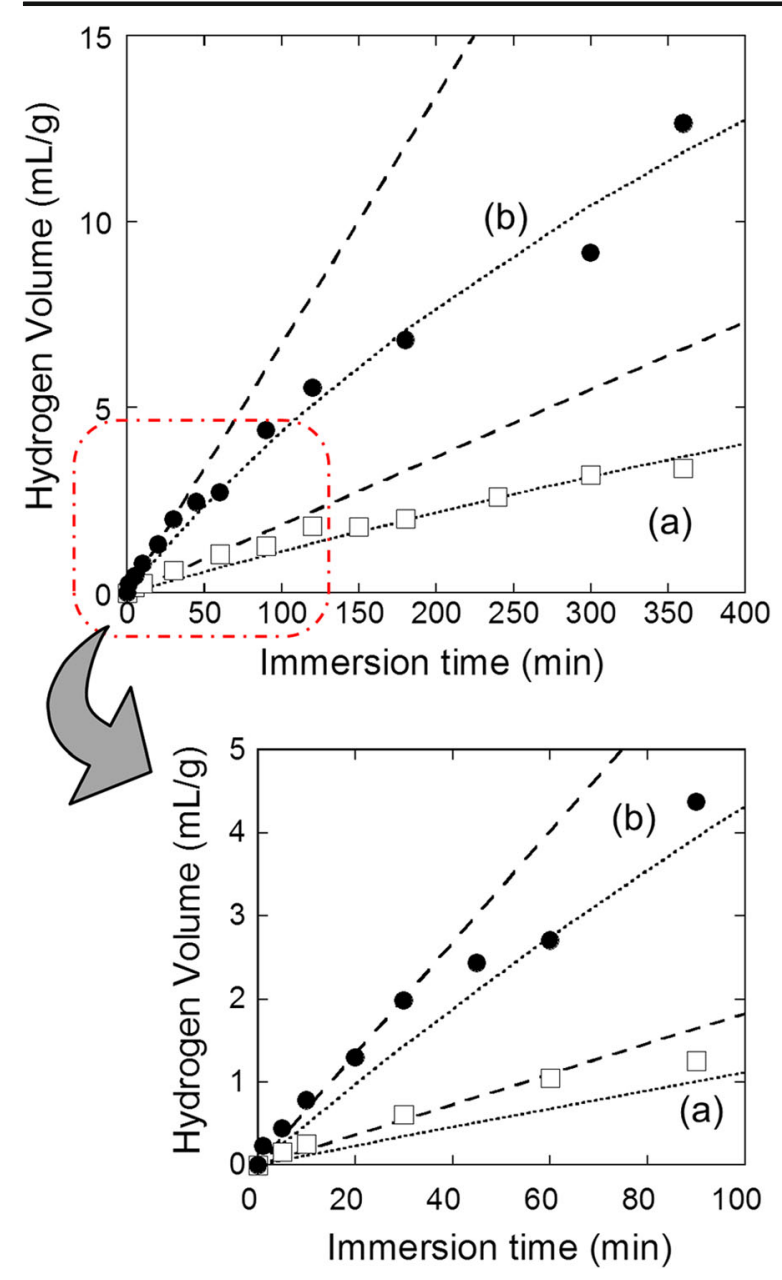

Fig. 1 Generated hydrogen volume vs the immersion time of $\mathrm{Si}$ nanopowder under the following conditions in ultrapure water: a as-prepared; b after etching with an HF solution. Si nanopowder was produced by use of the one-step milling method with $0.5-\mathrm{mm}$ diameter zirconia beads. Generated hydrogen volume was estimated from the hydrogen concentration in water. The dashed and dotted lines show the calculated relationship for the reactionlimited and migration-limited mechanisms, respectively. The lower portion shows the enlarged figure of the early stage of hydrogen generation from Si nanopowder

that $\mathrm{pH}$ of pancreatic juice is in the range between 7.6 and 8.9 , and therefore, the present result shows a possibility that $\mathrm{Si}$ nanopowder can generate hydrogen in bowels where the absorption efficiency is high.

The above result clearly shows that $\mathrm{Si}$ nanopowder reacts with water having neutral $\mathrm{pH}$, resulting in hydrogen evolution. The hydrogen generation ratio for the solution with $\mathrm{pH}$ of 8.0 (plot b) in the initial reaction stage between 0 and $5 \mathrm{~min}$ is approximately 40 times higher than that for ultrapure water (plot a). The ratio for shorter initial period is likely to be higher because the

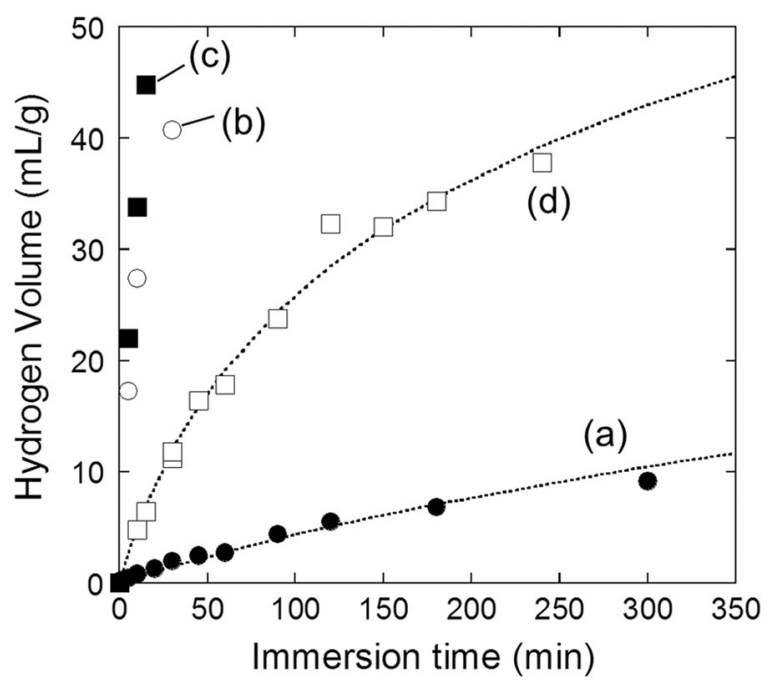

Fig. 2 Generated hydrogen volume vs the immersion time of $\mathrm{Si}$ nanopowder in the following solutions: a ultrapure water; $\mathbf{b}$ water with $\mathrm{pH} 8.0$; $\mathbf{c}$ water with $\mathrm{pH} 8.6$; $\mathbf{d}$ tap water with $\mathrm{pH}$ 7.1 7.4. Si nanopowder was produced by use of the one-step milling method with $0.5-\mathrm{mm}$ diameter zirconia beads. Si nanopowder was etched with an HF solution to remove silicon oxide before immersion

reaction at $5 \mathrm{~min}$ for the $\mathrm{pH} 8.0$ solution may already be retarded by the formation of an oxide layer. This result indicates that the reacting species is hydroxide ions $(\mathrm{OH})$, but not water molecules. Therefore, the reaction formulae are written as

$\mathrm{Si}+2 \mathrm{OH}^{-} \rightarrow \mathrm{SiO}_{2}+\mathrm{H}_{2}+2 e$

$2 \mathrm{H}_{2} \mathrm{O}+2 e \rightarrow \mathrm{H}_{2}+2 \mathrm{OH}^{-}$

and the total reaction formula is expressed as

$\mathrm{Si}+2 \mathrm{H}_{2} \mathrm{O} \rightarrow \mathrm{SiO}_{2}+2 \mathrm{H}_{2}$

In cases where reaction (1) is the rate-determining step, the reaction rate is proportional to the square of the concentration of $\mathrm{OH}^{-}$ions because of the secondorder reaction. Reaction (1) generates electrons in the oxide conduction band, and they are accepted by water molecules, resulting in water decomposition, and generation of hydrogen molecules and $\mathrm{OH}^{-}$ions (reaction (2)). Therefore, reaction (1) followed by reaction (2) does not change the concentration of $\mathrm{OH}^{-}$ions. To confirm this conclusion, we have performed the following experiment: Using a $\mathrm{pH} 9.0$ solution, $\mathrm{pH}$ of the solution was found to change to 8.6 after hydrogen evolution. Assuming that hydrogen evolution proceeded by consuming $\mathrm{OH}^{-}$ions, the equivalent $\mathrm{HCl}$ solution was added to the 
$\mathrm{pH} 9.0$ solution, and in this case, $\mathrm{pH}$ was observed to change to 6.6. This result demonstrates that the hydrogen generation reaction does not consume $\mathrm{OH}^{-}$ions. The slight decrease in $\mathrm{pH}$ from 9.0 to 8.6 was most likely to be caused by dissolution of $\mathrm{CO}_{2}$ in the air.

Figure 3 shows the XPS spectra in the Si $2 p$ region of $\mathrm{Si}$ nanopowder. For as-prepared Si nanopowder (spectrum a), two peaks were observed at 99.6 and $102.6 \mathrm{eV}$, attributable to Si and silicon oxide, respectively (Himpsel et al. 1988; Kobayashi et al. 1991). Taking into account that each $\mathrm{Si} 2 \mathrm{p}$ peak contained two components due to $\mathrm{Si}$ $2 p_{3 / 2}$ and $2 p_{1 / 2}$ having the same widths and the intensity ratio of 2:1 separated by $0.612 \mathrm{eV}$ (Bozek et al. 1990), the observed XPS spectra were deconvoluted, and only the Si $2 p_{3 / 2}$ components were shown by the dotted line in the spectra. The Si $2 \mathrm{p}_{3 / 2}$ components at 100.3, 101.9, and $103.3 \mathrm{eV}$ are most probably attributable to $\mathrm{Si}$ atoms to

(a)

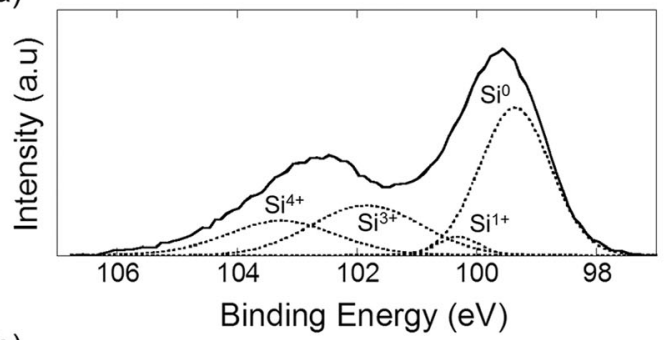

(b)

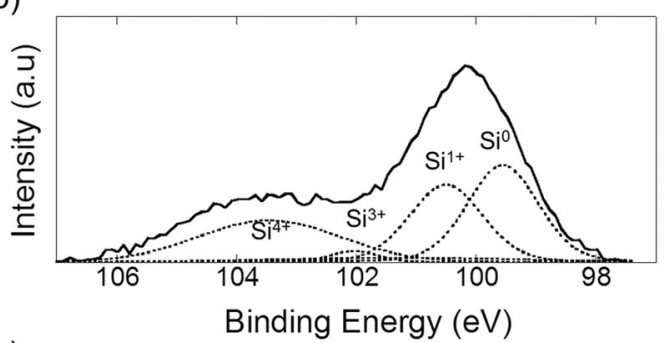

(c)

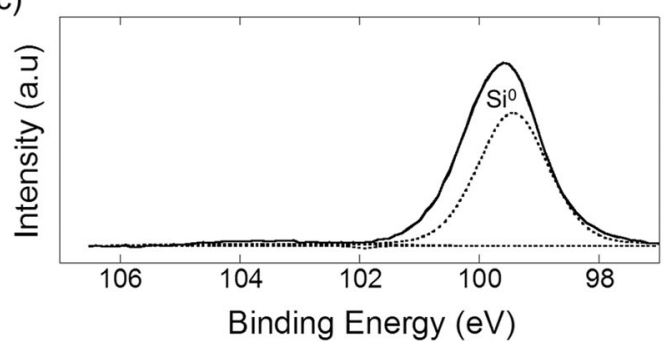

Fig. 3 XPS spectra in the Si $2 p$ region for Si nanopowder with the following conditions: a as-prepared Si nanopowder; $\mathbf{b}$ after reaction of as-prepared Si nanopowder with ultrapure water for $360 \mathrm{~min} ; \mathbf{c}$ after etching with an HF solution; $\mathbf{d}$ after reaction of HF-etched Si nanopowder with ultrapure water for $24 \mathrm{~h}$; e after reaction of HF-etched Si nanopowder with water having $\mathrm{pH} 8.0$ which one, three, and four oxygen atoms (hereafter, denoted as $\mathrm{Si}^{+}, \mathrm{Si}^{3+}$, and $\mathrm{Si}^{4+}$, respectively) are bound each (Himpsel et al. 1988; Kobayashi et al. 1991). The intensity of the $\mathrm{Si}^{2+}$ species was negligibly low. After reaction of as-prepared $\mathrm{Si}$ nanopowder with ultrapure water for $360 \mathrm{~min}$ (spectrum b), the intensities of the peaks due to $\mathrm{Si}^{4+}$ and $\mathrm{Si}^{+}$increased while those due to $\mathrm{Si}^{3+}$ and $\mathrm{Si}^{0}$ decreased.

After HF etching of as-prepared Si nanopowder (spectrum c), the peak due to silicon oxide disappeared almost completely, indicating removal of oxide. After reaction of HF-etched Si nanopowder with ultrapure water (spectrum d) and water having $\mathrm{pH} 8.0$ for $24 \mathrm{~h}$ (spectrum e), the oxide peak was observed. In the latter case, the peak due to oxide was much stronger than the former case, and deconvolution showed that oxide consisted of $\mathrm{Si}^{4+}$ species (i.e., $\mathrm{SiO}_{2}$ ) without suboxide species.

(d)

(e)
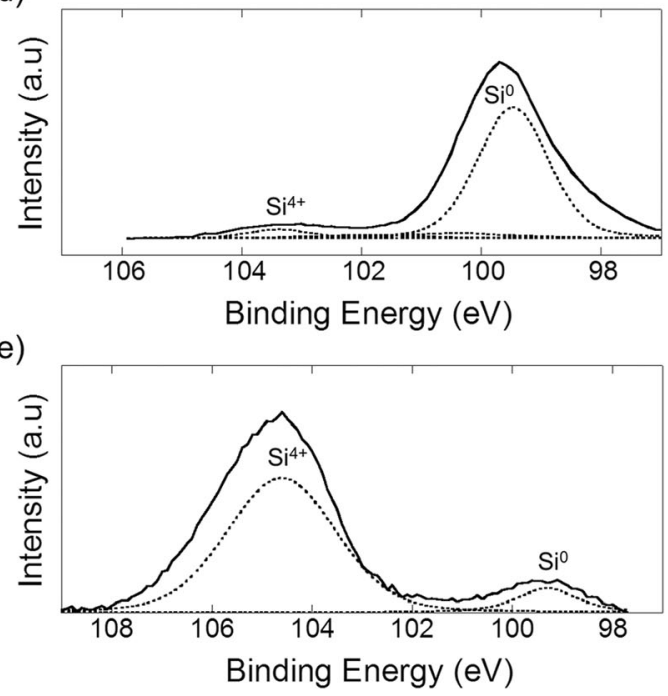

for $24 \mathrm{~h}$. The dotted lines indicate components of unreacted $\mathrm{Si}$ $\left(\mathrm{Si}^{0}\right)$, and $\mathrm{Si}$ atoms to which one $\left(\mathrm{Si}^{1+}\right)$, three $\left(\mathrm{Si}^{3+}\right)$, and four oxygen $\left(\mathrm{Si}^{4+}\right)$ atoms are bound each. For the deconvoluted peaks, only the Si $2 p_{3 / 2}$ components are depicted. Photoelectrons were collected in the surface-normal direction 
For elucidation of the rate-determining step (i.e., surface reaction or migration of $\mathrm{OH}^{-}$ions through silicon oxide), the thickness of a silicon oxide layer on $\mathrm{Si}$ nanopowder should be determined (Deal and Grove 1965), which can be done from analysis of the observed XPS spectra, as explained below. The size of Si nanopowder was estimated from the analysis of the XRD data assuming spherical shape. However, the XPS spectra cannot be analyzed assuming the spherical shape, and instead, a cylindrical shape which is reported to express the spherical shape reasonably well for estimation of the overlayer thickness (Renault et al. 2003) is adopted. Using the area intensity ratio of the oxide peak, $I_{\text {oxide }}$, to that of the unreacted $\mathrm{Si}$ peak, $I_{S i}$, and assuming the cylindrical structure with the radius, $R$, and the height, $H$, the oxide thickness, $l_{\text {oxide }}$, can be estimated using the following equation (Renault et al. 2003):

$\frac{I_{\text {oxide }}}{I_{S i}}=\frac{n_{\text {oxide }} \sigma_{\text {oxide }} \lambda_{\text {oxide }}}{n_{S i} \sigma_{S i} \lambda_{S i}} \times \frac{\left(R-l_{\text {oxide }}\right)^{2}\left[1-\exp \left(\frac{l_{\text {oxide }}}{\lambda_{\text {oxide }}}\right)\right]+l_{\text {oxide }}\left(2 R-l_{\text {oxide }}\right)\left[1-\exp \left(-\frac{H}{\lambda_{\text {oxide }}}\right)\right]}{\left(R-l_{\text {oxide }}\right)^{2} \exp \left(-\frac{l_{\text {oxide }}}{\lambda_{\text {oxide }}}\right)\left[1-\exp \left(-\frac{H-l_{\text {oxide }}}{\lambda_{S i}}\right)\right]}$

where $n, \sigma$, and $\lambda$ are the number density of Si atoms, the photoemission cross-section, and the photoelectron mean free path, respectively, the subscripts, oxide and $\mathrm{Si}$, denote values for silicon oxide and $\mathrm{Si}$, respectively. Hereafter, the oxide thickness is estimated assuming $H=R$ and $R=$ $11.7 \mathrm{~nm}$ (i.e., the average size of $\mathrm{Si}$ nanopowder determined from the width of the XRD peaks). The detailed information concerning the size of Si nanopowder is given in the supplementary material. Using Eq. (4), and adopting $2.5 \mathrm{~nm}$ for $\lambda_{S i}, 2.9 \mathrm{~nm}$ for $\lambda_{\text {oxide }}$ (Kobayashi et al. 2003) and 1.1 for $\sigma_{\text {oxide }} / \sigma_{S i}$ (Hochella and Carim 1988), the oxide thickness on as-prepared Si nanopowder (cf. Fig. 3a) is estimated to be $1.6 \mathrm{~nm}$. In this estimation, the peaks due to $\mathrm{Si}^{4+}$ and $\mathrm{Si}^{3+}$ are regarded as oxide, but not $\mathrm{Si}^{+}$. The intensity of the $\mathrm{Si}^{2+}$ peak was negligibly low.

It is confirmed from the XPS measurements that after the hydrogen evolution reaction stopped, a $4.8 \mathrm{~nm}$ oxide layer was formed on Si nanopowder (cf. Fig. 3e). This result indicates that the $4.8 \mathrm{~nm}$ oxide layer acts as complete migration barrier for $\mathrm{OH}^{-}$ions.

It should be noted that until the formation of the $4.8 \mathrm{~nm} \mathrm{SiO}_{2}$ layer, $\sim 300 \mathrm{~mL} / \mathrm{g}$ hydrogen was observed to be generated, which corresponded to reaction of $\sim 18 \%$ Si for hydrogen generation. This amount of hydrogen corresponds to that contained in $\sim 16 \mathrm{~L}$ saturated hydrogen-rich water. Using Si nanopowder, such a large amount of hydrogen can be generated in our body.

Assuming spherical shape for $\mathrm{Si}$ nanopowder, the volume of generated hydrogen, $V_{H}$, is given by

$V_{H}=a_{1}\left[r_{0}^{3}-\left(r_{0}-\Delta r(t)\right)^{3}\right]$ where $r_{0}$ is the initial radius of Si nanopowder, $\Delta r$ is the decrease of the radius of Si nanopowder consumed for oxide formation, $t$ is the reaction time, and $a_{1}$ is the constant. Considering that the volume of consumed $\mathrm{Si}$ for oxide formation is 0.46 times that of formed oxide (Sze and Ng 2006), we have

$r_{0}^{3}-\left[r_{0}-\Delta r(t)\right]^{3}=0.46\left[\left\{r_{0}-\Delta r(t)+l_{\text {oxide }}(t)\right\}^{3}-\left\{r_{0}-\Delta r(t)\right\}^{3}\right]$

In cases where the reaction at the $\mathrm{Si}$ surface is the rate-determining step (Deal and Grove 1965), the silicon oxide thickness, $l_{\text {oxide }}$, is given by

$l_{\text {oxide }}=a_{2} t$

where $a_{2}$ is the constant. Using Eqs. (5), (6), and (7), the relationship between the generated hydrogen volume and the reaction time can be calculated, and the calculated result is given by the dashed lines in Fig. 1 .

When the oxide thickness exceeds a certain value, movement of $\mathrm{OH}^{-}$ions (i.e., migration) becomes ratedetermining. In cases where inward migration of negative ions is the rate-determining-step (Eley and Wilkinson 1960), the oxide thickness, $l_{\text {oxide }}$, is given by

$l_{\text {oxide }}=\frac{k T}{a_{3}} \ln \frac{a_{3} a_{4}\left(t+t_{0}\right)}{k T}-\frac{W}{a_{3}}$

where $a_{3}$ and $a_{4}$ are the constants, $W$ is the activation energy for migration of $\mathrm{OH}^{-}$ions in the absence of silicon oxide, and $t_{0}$ is written as

$t_{0}=\frac{k T}{a_{3} a_{4}} \exp \left[\frac{a_{4}}{k T}\left\{l_{\text {oxide }}(0)+\frac{W}{a_{4}}\right\}\right]$ 
Inserting $l_{\text {oxide }}$ obtained from Eqs. (8) and (9) into Eq. (6), the relationship between the generated hydrogen volume, $V_{H}$, and the reaction time, $t$, can be calculated, and they are shown by the dotted lines in Figs. 1 and 2.

The calculated curves for the migration-limited case shown by the dotted lines in Figs. 1 and 2 well express the experimental results. For the migration-limited process, constants $a_{3}$ and $a_{4}$ in Eqs. (8) and (9) determine the generated hydrogen volume. Using the $a_{3}$ and $a_{4}$ values obtained from the curve fitting, the generated hydrogen volume after the reaction for $24 \mathrm{~h}$ is estimated to be $26.5 \mathrm{~mL} / \mathrm{g}$. The generated hydrogen volume can also be estimated from the thickness of the silicon oxide layer determined from the XPS spectrum (cf. Fig. 3d). Thus estimated hydrogen volume of $28.3 \mathrm{~mL} / \mathrm{g}$ is in good agreement with that estimated from the curve fitting, which also verifies the migration-limited mechanism.

Plot $b$ for Si nanopowder after HF-etching in the reaction time region up to $30 \mathrm{~min}$ deviates from the calculated curve for the migration-limited case while it is well expressed by the dashed line for the reactionlimited case (cf. enlarged figure of Fig. 1). HF etching removes silicon oxide almost completely. Therefore, migration of $\mathrm{OH}^{-}$ions through silicon oxide proceeds smoothly, leading to the reaction-limited mechanism. The thickness of the $\mathrm{SiO}_{2}$ layer on HF-etched $\mathrm{Si}$ nanopowder after the reaction for $30 \mathrm{~min}$ is estimated to be $0.13 \mathrm{~nm}$ from the XPS spectrum for as-etched $\mathrm{Si}$ nanopowder and the generated hydrogen volume. This $\mathrm{SiO}_{2}$ thickness is in reasonable agreement with the $\mathrm{Si}-\mathrm{O}$ bond length of $0.15 \sim 0.16 \mathrm{~nm}$, indicating the formation of approximately monolayer $\mathrm{Si}-\mathrm{O}$ structure. Therefore, it can be concluded that the reaction at the $\mathrm{Si} / \mathrm{SiO}_{2}$ interface is the rate-determining step until monolayer $\mathrm{Si}-\mathrm{O}$ bonds are formed, and after the formation of monolayer $\mathrm{Si}-\mathrm{O}$ bonds, migration of $\mathrm{OH}^{-}$ions through $\mathrm{SiO}_{2}$ becomes rate-limiting. The small $\mathrm{SiO}_{2}$ thickness at the mechanism-changing point is due to the reaction at room temperature at which movement of oxidizing species is very slow in contrast to thermal oxidation of $\mathrm{Si}$ at temperatures higher than $800{ }^{\circ} \mathrm{C}$.

In the case of Si nanopowder without HF etching, a $1.6 \mathrm{~nm}$ silicon oxide layer is present on the nanocrystalline Si surfaces (cf. Fig. 3a). Removal of the oxide layer by HF etching greatly increased the reaction rate (cf. Fig. 1a, b), indicating that the oxide layer retarded the reaction. In fact, the calculated curve for the reaction-limited process (the dashed line in Fig. 1), which curve is determined from the silicon oxide thickness, largely deviates from the experimental result shown in Fig. 1a. On the other hand, the calculated curve for the migration-limited mechanism shown by the dotted line can well express the experimental result. The XPS measurements show that for Si nanopowder without HF etching, the oxide thickness increased only slightly from 1.56 to $1.60 \mathrm{~nm}$ after reaction for $360 \mathrm{~min}$ (cf. Fig. 3b). It is noted that the logarithmic curve for the migration-limited mechanism in this narrow thickness region is almost linear.

In the case of the reaction with tap water (cf. Fig. 2d), the experimental result is well fitted by the calculated curve for the migration-limited mechanism. For the very initial reaction stage with the oxide thickness less than $0.13 \mathrm{~nm}$ (i.e., generated hydrogen volume less than $2.0 \mathrm{~mL} / \mathrm{g}$ ), the reaction is likely to be the ratedetermining step, but due to the short period for the reaction-limited process, it was not clearly observed in plot d in Fig. 2. Therefore, it can be concluded that in the case of $\mathrm{pH}$ higher than 7.4, the hydrogen generation reaction follows the migration-limited kinetics in almost the whole reaction period.

Figure 4 shows the volume of hydrogen generated by the reaction of Si nanopowder produced by the one-step (plot a) and two-step (plot b) milling methods with ultrapure water. Both the plots were nearly linear, and the rate of an increase in the hydrogen volume for plot $b$ in

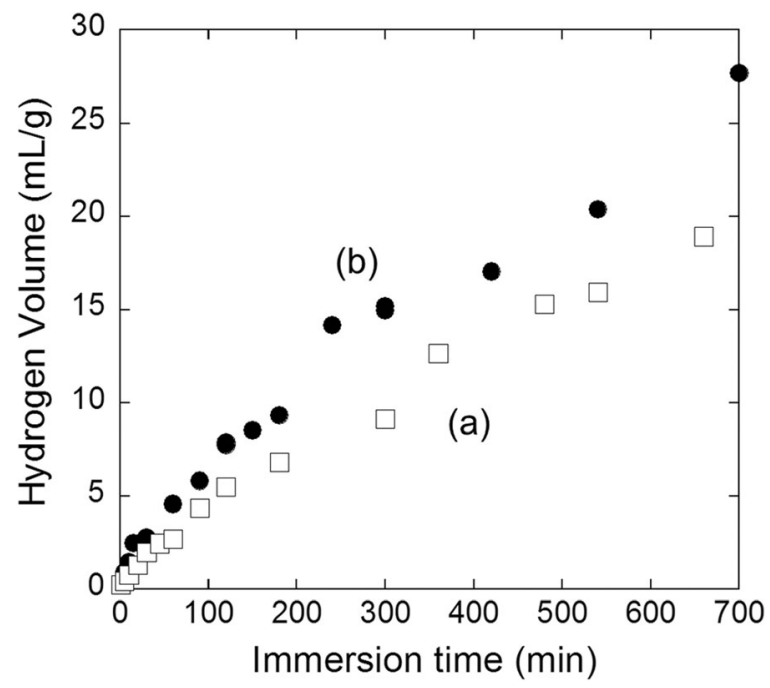

Fig. 4 Generated hydrogen volume vs the time of immersion in ultrapure water for $\mathrm{Si}$ nanopowder produced by the following method: a one-step milling; b two-step milling. For one-step and two-step milling, $0.5-\mathrm{mm}$ diameter zirconia beads and those plus 0.3 -mm diameter zirconia beads were employed. Si nanopowders were treated with an HF solution before immersion 
the initial hydrogen generation stage where the reaction was the rate-determining step was approximately 1.5 times of that for plot a.

The average diameters of Si crystallites for one-step and two-step milling determined from the XRD measurements (cf. Fig. S1 in supplementary material) are 23.4 and $13.8 \mathrm{~nm}$, respectively, and the surface areas of the former and latter Si nanopowders are roughly estimated to be 110 and $190 \mathrm{~m}^{2} / \mathrm{g}$, respectively. The ratio of the surface areas of 1.7 shows a reasonable agreement with the ratio of the hydrogen generation rates of 1.5. This result indicates that the reactivity of Si nanopowder is determined by the Si crystallite size. It should be noted that the surface areas estimated from the size of aggregated Si nanopowders are nearly the same for one-step and two-step milling, i.e., 12.8 and $13.4 \mathrm{~m}^{2} / \mathrm{g}$, respectively (cf. Fig. S4 in supplementary material). The above result shows that the hydrogen generation rate strongly depends on the crystallite size of Si nanopowder, but it is nearly independent of the size of agglomerates.

The specific surface areas are determined to be 74 and $143 \mathrm{~m}^{2} / \mathrm{g}$, respectively, using the nitrogen physisorption method. The estimated specific surface areas are $\sim 40 \mathrm{~m}^{2} /$ g smaller than the surface areas determined from the average crystallite sizes. This difference may be due to the presence of micropores (i.e., $<2 \mathrm{~nm}$ ) to which nitrogen molecules cannot enter to form a second nitrogen layer (physisorbed layer). Because of the smaller size of $\mathrm{OH}^{-}$ions than a part of micropores, the ions may be able to enter them and the ratio of the effective surface areas between two-step and one-step milled Si nanopowders is likely to be smaller than the ratio of the specific surface areas determined by the BET method.

As explained above, it is clearly shown that $\mathrm{Si}$ nanopowder reacts with water in the neutral $\mathrm{pH}$ region to generate hydrogen. Since Si nanopowder and its oxide are nonpoisonous, Si nanopowder can be taken to generate hydrogen in the human body. No reaction proceeds in a stomach where $\mathrm{pH}$ is low ( $\mathrm{pH}$ of gastric juices: 1.5 2.0), while it reacts with $\mathrm{OH}^{-}$ions in small intestine where pancreatic juice with $\mathrm{pH}$ in the range between 7.5 and 8.8 is injected and also absorption efficiency is high.

\section{Conclusion}

We have shown that Si nanopowder reacts with water even with the neutral $\mathrm{pH}$ range between 7.0 and 8.6, generating hydrogen. The hydrogen generation rate greatly increases with $\mathrm{pH}$, while the change of $\mathrm{pH}$ after the hydrogen generation reaction is negligibly low compared with that estimated assuming that $\mathrm{OH}^{-}$ions are consumed for hydrogen generation. These results show that (i) the reacting species is $\mathrm{OH}^{-}$ions and (ii) the concentration of $\mathrm{OH}^{-}$ions remains unchanged during the hydrogen generation reaction. The unchanged $\mathrm{pH}$ indicates the reaction mechanism that $\mathrm{OH}^{-}$ions are consumed in the initial reaction stage but electrons generated in the initial reaction stage are captured by water molecules, leading to generation of $\mathrm{OH}^{-}$ions. Analysis of the relationship between the generated hydrogen volume and the reaction time confirms the reaction mechanism involving negative ions, i.e., $\mathrm{OH}^{-}$ions. The surface reaction is the rate-determining step until the formation of monolayer $\mathrm{Si}-\mathrm{O}$ bonds, and afterward, migration of $\mathrm{OH}^{-}$ions through the oxide layer becomes ratedetermining. The reaction of $\mathrm{Si}$ nanopowder to generate hydrogen stops when the thickness of a $\mathrm{SiO}_{2}$ layer on $\mathrm{Si}$ nanopowder reaches $4.8 \mathrm{~nm}$. The reaction rate strongly depends on the crystallite size but not on the size of agglomerates of Si nanopowder.

Acknowledgements This research is supported by the Center of Innovation Program from Japan Science and Technology Agency, JST.

\section{Compliance with ethical standards}

Funding This study was funded by the Center of Innovation Program from Japan Science and Technology Agency, JST.

Conflict of interest The authors declare that they have no conflict of interest.

Open Access This article is distributed under the terms of the Creative Commons Attribution 4.0 International License (http:// creativecommons.org/licenses/by/4.0/), which permits unrestricted use, distribution, and reproduction in any medium, provided you give appropriate credit to the original author(s) and the source, provide a link to the Creative Commons license, and indicate if changes were made.

\section{References}

Bahruji H, Bowker M, Davies PR (2009) Photoactivated reaction of water with silicon nanoparticles. Inter J Hydrogen Energy 34:8504-8510. doi:10.1016/j.ijhydene.2009.08.039

Bozek JD, Bancroft GM, Cutler JN, Tan KH (1990) Vibrationally resolved Core-level photoelectron spectroscopy: Si $2 p$ levels of $\mathrm{SiH}_{4}$ and $\mathrm{SiF}_{4}$ molecules. Phys Rev Lett 22:2757-2760. doi:10.1103/PhysRevLett.65.2757 
Cadenas E, Davies K (2000) Mitochondrial free radical generation, oxidative stress, and aging. Free Radic Biol Med 29: 222-230. doi:10.1016/S0891-5849(00)00317-8

Charvin D, Vanhoutte P, Pages C, Borrelli E, Caboche J (2005) Unraveling a role for dopamine in Huntington's disease: the dual role of reactive oxygen species and D2 receptor stimulation. Proc Natl Acad Sci 102:1221812223. doi:10.1073/pnas.0502698102

Deal BE, Grove AS (1965) General relationship for the thermal oxidation of silicon. J Appl Phys 36:3770-3778. doi:10.1063/1.1713945

Eley DD, Wilkinson PR (1960) Adsorption and oxide formation on Aluminium films. Proc R Soc London Ser A 254:327342. doi:10.1098/rspa.1960.0023

Erogbogbo F, Lin T, Tucciarone PM, Lajoie KM, Lai L, Latki GD, Prasad PN, Swihart MT (2013) On-demand hydrogen generation using Nanosilicon: splitting water without light, heat, or electricity. Nano Lett 13:451-456. doi:10.1021/nl304680w

$\mathrm{Fu}$ Y, Ito M, Fujita Y, Ito M, Ichihara M, Masuda A, Suzuki Y, Maesawa S, Kajita Y, Hirayama M, Ohsawa I, Ohta S, Ohno K (2009) Molecular hydrogen is protective against 6hydroxydopamine-induced nigrostriatal degeneration in a rat model of Parkinson's disease. Neurosci Lett 453:81-85. doi:10.1016/j.neulet.2009.02.016

Garner B, Davies JM, Truscott RJW (2000) Formation of hydroxyl radicals in the human lens is related to the severity of nuclear cataract. Exp Eye Res 70:81-88. doi:10.1006/exer.1999.0754

Higashi GS, Becker RS, Chabal YJ, Becker A (1991) Comparison of $\mathrm{Si}(111)$ surfaces prepared using aqueous solutions of NH4F versus HF. J Appl Phys Lett 58:1656-1658. doi:10.1063/1.105155

Himpsel FJ, McFeely FR, Taleb-Ibrahimi A, Yarmoff JA, Hollinger $\mathrm{G}$ (1988) Microscopic structure of the $\mathrm{SiO}_{2} / \mathrm{Si}$ interface. Phys Rev B 38:6084-6096. doi:10.1103/PhysRevB.38.6084

Hochella MF Jr, Carim AH (1988) A reassessment of electron escape depths in silicon and thermally grown silicon dioxide thin films. Surf Sci 197:L260-L268. doi:10.1016/0039-6028 (88)90625-5

Ihara Y, Chuda M, Kuroda S, Hayabara T (1999) Hydroxyl radical and superoxide dismutase in blood of patients with Parkinson's disease: relationship to clinical data. J Neurol Sci 170:90-95. doi:10.1016/S0022-510X(99)00192-6

Imamura K, Kimura K, Fujie S, Kobayashi H (2016) Hydrogen generation from water using $\mathrm{Si}$ nanopowder fabricated from swarf. J Nanopart Res 18:116. doi:10.1007/s11051-0163418-x

Iuchi K, Imoto A, Kamimura N, Nishimaki K, Ichimiya H, Yokota $\mathrm{T}$, Ohta S (2016) Molecular hydrogen regulates gene expression by modifying the free radical chain reaction dependent generation of oxidized phospholipid mediators. Sci Rep 6: 18971. doi:10.1038/srep 18971

Jakob P, Chabal YJ, Raghavachari K, Becker RS, Becker AJ (1992) Kinetic model of the chemical etching of Si(111) surfaces by buffered HF solutions. J Surf Sci 275:407-413. doi:10.1016/0039-6028(92)90813-L

Kagawa A, Katsura K, Mizumoto M, Tagawa Y, Masiko Y (2012) Influence of hydrogen discharged from Palladium Base hydrogen storage alloys on cancer cells. Mater Sci Forum 706709:520-525. doi:10.4028/www.scientific.net/MSF.706709.520
Kajiyama S, Hasegawa G, Asano M, Hosoda H, Fukui M, Nakamura N, Kitawaki J, Imai S, Nakano K, Ohta M, Adachi T, Obayashi H, Yoshikawa T (2008) Supplementation of hydrogen-rich water improves lipid and glucose metabolism in patients with type 2 diabetes or impaired glucose tolerance. Nutrition Res 28:137143. doi:10.1016/j.nutres.2008.01.008

Kamimura N, Nishimaki K, Ohsawa I, Ohta S (2011) Molecular hydrogen improves obesity and diabetes by inducing hepatic FGF21 and stimulating energy metabolism in $\mathrm{db} / \mathrm{db}$ Mice. Obesity 19:1396-1403. doi:10.1038/oby.2011.6

Kato S, Saitoh Y, Iwai K, Miwa N (2012) Hydrogen-rich electrolyzed warm water represses wrinkle formation against UVA ray together with type-I collagen production and oxidativestress diminishment in fibroblasts and cell-injury prevention in keratinocytes. J Photochem Photobiol B: Biology 106:24 33. doi:10.1016/j.jphotobiol.2011.09.006

Kobayashi H, Ishida T, Nakato Y, Tsubomura H (1991) Mechanism of carrier transport in highly efficient solar cells having indium tin oxide/Si junctions. J Appl Phys 69:17361743. doi:10.1063/1.347220

Kobayashi H, Asuha MO, Takahashi M, Iwasa H (2003) Nitric acid oxidation of $\mathrm{Si}$ to form ultrathin silicon dioxide layers with a low leakage current density. J Appl Phys 94:73287335. doi: $10.1063 / 1.1621720$

Li J, Wang C, Zhang JH, Cai JM, Cao YP, Sun XJ (2010) Hydrogen-rich saline improves memory function in a rat model of amyloid-beta-induced Alzheimer's disease by reduction of oxidative stress. Brain Res 1328:152-161. doi:10.1016/j.brainres.2010.02.046

Litvinenko S, Alekseev S, Lysenko V, Venturello A, Geobaldo F, Gulina L, Kuznetsov G, Tolstoy V, Skryshevsky V, Garrone E, Barbier D (2010) Hydrogen production from nano-porous Si powder formed by stain etching. Inter J Hydrogen Energy 35:6773-6778. doi:10.1016/j.ijhydene.2010.04.041

Maeda M, Imamura K, Matsumoto T, Kobayashi H (2014) Fabrication of Si nanoparticles from Si swarf and application tosolar cells. Appl Surf Sci 312:39-42. doi:10.1016/j. apsusc.2014.02.131

Matsumoto T, Maeda M, Furukawa J, Kim WB, Kobayashi H (2014) Si nanoparticles fabricated from Si swarf by photochemical etching method. J Nanopart Res 16:2240. doi:10.1007/s11051-013-2240-y

Matsumoto T, Maeda M, Kobayashi H (2016) Photoluminescence enhancement of adsorbed species on Si nanoparticles. Nanoscale Res Lett 11:7. doi:10.1186/s11671-015-1220-9

Maurizi CP (2001) Alzheimer's disease: roles for mitochondrial damage, the hydroxyl radical, and cerebrospinal fluid deficiency of melatonin. Med Hypotheses 57:156-160. doi:10.1054/mehy.2001.1324

Nagata K, Kamimura N, Mikami T, Ohsawa I, Ohta S (2009) Consumption of Molecular hydrogen prevents the stress-induced impairments in hippocampusdependent learning tasks during chronic physical restraint in Mice. Neuropsychopharmacology 34:501508. doi:10.1038/npp.2008.95

Ohsawa I, Ishikawa M, Takahashi K, Watanabe M, Nishimaki K, Yamagata K, Katsura K, Katayama Y, Asoh S, Ohta S (2007) Hydrogen acts as a therapeutic antioxidant by selectively reducing cytotoxic oxygen radicals. Nat Med 13:688-694. doi: $10.1038 / \mathrm{nm} 1577$ 
Pillai S, Oresajo C, Hayward J (2005) Ultraviolet radiation and skin aging: roles of reactive oxygen species, inflammation and protease activation, and strategies for prevention of inflammationinduced matrix degradation - a review. Int J Cosmet Sci 27:1734. doi:10.1111/j.1467-2494.2004.00241.x

Renault O, Marlier R, Barrett NT, Martinez E, Baron T, Gely M, De Salvo B (2003) Modeling the XPS Si 2p core-level intensities of silicon nanocrystals for determination of oxide shell thickness. Surf Interface Anal 38:486-488. doi:10.1002 /sia.2223
Sze SM, Ng KK (2006) Physics of semiconductor devices, Third edn. John Wiley \& Sons, Inc., New York, pp 790-791

Yoon YS, Sajo ME, Ignacio RM, Kim SK, Kim CS, Lee KJ (2014) Positive effects of hydrogen water on 2,4-dinitrochlorobenzeneinduced atopic dermatitis in NC/Nga Mice. J Biol Pharm Bull 37:1480-1485. doi:10.1248/bpb.b14-00220

Yoritaka A, Takanashi M, Hirayama M, Nakahara T, Ohta S, Hattori N (2013) Pilot study of $\mathrm{H}_{2}$ therapy in Parkinson's disease: a randomized double-blind placebo-controlled trial. Mov Disord 28:836-839. doi:10.1002/mds.25375 